\title{
General Dentists and Pediatric Dental Patients: The Role of Dental Education
}

\begin{abstract}
John P. Rich III, M.P.H.; Lloyd Straffon, D.D.S., M.S.; Marita Rohr Inglehart, Dr.phil.habil. Abstract: The objective of this study was to investigate whether undergraduate dental education affects general dentists' practice characteristics, attitudes, and professional behavior concerning the treatment of pediatric patients. Data were collected with a self-administered mailed survey from 241 general dentists who were members of the Michigan Dental Association (response rate $=48.2$ percent). While 40.4 percent of the respondents reported that their dental education had prepared them well to treat child patients, only 33.4 percent indicated that their clinical education had prepared them well. The level of educational preparedness was significantly correlated with a) practice characteristics such as how well the practice was set up to treat children and how knowledgeable and comfortable the staff was concerning providing care for children, b) attitudes concerning the treatment of child patients, and c) professional behavior such as the types of services provided for child patients versus the number of referrals made. The findings strongly suggest that educational experiences concerning the treatment of pediatric dental patients will shape future dental care providers' attitudes and professional behavior. Given the lack of access to dental care for children, it seems crucial to carefully evaluate undergraduate dental curricula to ensure that future dental care providers receive sufficient educational and especially clinical experiences concerning the treatment of child patients.
\end{abstract}

Mr. Rich is a fourth-year dental student, University of Michigan School of Dentistry; Dr. Straffon is Emeritus Professor of Dentistry, Department of Orthodontics and Pediatric Dentistry, University of Michigan School of Dentistry; and Dr. Inglehart is Associate Professor, Department of Periodontics and Oral Medicine, School of Dentistry, and Adjunct Associate Professor, Department of Psychology, College of Literature, Science, and Arts, University of Michigan. Direct correspondence and requests for reprints to Dr. Marita Rohr Inglehart, Department of Periodontics and Oral Medicine, School of Dentistry, University of Michigan, Ann Arbor, MI 48109-1078; 734-763-8073 phone; 734-763-5503 fax; mri@umich.edu.

Key words: pediatric patients, children, dental care, underserved patients, access to care, dental education

Submitted for publication 5/2/06; accepted 8/19/06

$\mathrm{P}$ ediatric patients were one of the patient groups described as being underserved in the U.S. surgeon general's report on oral health. ${ }^{1}$ While the prevalence of caries among children in the United States has decreased since 1970, the rate of childhood caries is still surprisingly high. ${ }^{1}$ In addition, certain groups of children, especially socioeconomically disadvantaged children, children from underrepresented minority backgrounds, and children with special needs, are especially vulnerable to poor oral health and problems with access to dental care. For example, 25 percent of children in 2006 had 80 percent of the total caries diagnosed in the United States. ${ }^{2}$ In addition, in a study published in 1999, 57 percent of parents who reported that their child had unmet health care needs described these needs as being related to their child's dental health. ${ }^{2}$ Children with unmet dental health care needs were more likely to experience problems with their physical development, ${ }^{3,4}$ a loss of school days, and increased days with restricted activity, ${ }^{5-7}$ and they may have a diminished ability to learn. ${ }^{8-11}$ Making sure that children receive the oral health care services they need is therefore crucial to ensure that they have good general health and a positive quality of life and can live up to their academic potential.

While a study by Seale and Casamassimo in 2003 showed that the majority of general dentists in the United States do treat child patients, 9 percent of their respondents did not treat children between the ages of zero and fourteen years. In addition to the 9 percent of general dentists who did not treat child patients under the age of fourteen years at all, 73 percent of general dentists refused to treat children from six to eighteen months, 28 percent did not treat children between eighteen months and three years, and 2 percent did not treat children between four and six years of age. ${ }^{12}$ While only 13 percent of the respondents in this study indicated that they were not adequately trained to treat children, the results of the 
Seale and Casamassimo study indicate the need to explore whether varying levels of educational preparedness might be related to a lack of motivation to treat children and consequently dentists' professional behavior concerning the treatment of children. The results of a study at the University of Manitoba can be interpreted as direct support for this hypothesis. ${ }^{13}$ That study of dental school graduates showed that those dentists who graduated after the clinical pediatric program was substantially enhanced during their undergraduate training were more likely to perform complex procedures with children, were less likely to refer to a pediatric dentist, and were more likely to provide complex services to children under the age of five years than the graduates who had not received this improved training.

The powerful role that dental education plays in shaping future dentists' attitudes and professional behaviors concerning the treatment of underserved patient populations was documented in two recent studies. In 2006, Smith et al. explored the impact of dental education and dental students' and dentists' willingness to treat patients from underrepresented minority groups. They showed that dentists who agreed that their education had prepared them well to treat patients of different ethnic/racial backgrounds were more likely to treat underserved minority patients. ${ }^{14}$ In 2005, Dao et al. explored the relationship between dental education and dentists' willingness to treat special needs patients. ${ }^{15}$ These authors found that dentists who felt well prepared to treat special needs patients were more likely to treat both adult and pediatric patients with special needs and to provide services for patients with more diverse special needs than dentists who did not feel well prepared.

Our study complements these two earlier studies by exploring the influence of dental education upon dentists' willingness to treat pediatric patients. More specifically, the objective was to investigate whether undergraduate dental education affects general dentists' a) practice characteristics, b) attitudes, and c) professional behavior concerning the treatment of pediatric patients. It was hypothesized that dentists who reported more positive educational experiences with treating pediatric patients were more likely to set up their practice in a way that pediatric patients can be treated, had more positive attitudes concerning the treatment of pediatric patients, and provided more comprehensive treatment for children compared to dentists who reported less positive educational experiences.

\section{Methods}

This study was approved by the Institutional Review Board (IRB) for the Health Sciences at the University of Michigan in Ann Arbor, MI.

A self-administered survey was mailed to 500 randomly selected members of the Michigan Dental Association (MDA). A table of random numbers was used to select 500 addresses from the list that was provided by the MDA. The response rate was 48.2 percent $(\mathrm{N}=241)$. The majority of the respondents were male ( 81.7 percent) and white ( 84.6 percent) and had graduated from one of the two dental schools in the state of Michigan (University of Michigan: 56.8 percent; University of Detroit Mercy: 26.6 percent). They were on average 48.16 years old (age range: twenty-six to eighty-four years) and had graduated from dental school between 1945 and 2003. Only seventeen of the 241 respondents reported having done any graduate work, and only one respondent had done graduate work in pediatric dentistry.

The survey was mailed to the study subjects along with a cover letter written by the dean of the University of Michigan School of Dentistry and a self-addressed stamped envelope. The cover letter explained the purpose of the survey to the respondents and asked for their support of the research. The respondents returned the survey anonymously in the envelope provided.

The survey consisted of twenty-one questions. The first group of questions was concerned with the respondents' background, including their gender, age, educational experiences, and general practice characteristics such as the location of the practice. Questions in the second section of the survey focused on the dentists' perceptions of their educational experiences concerning the treatment of pediatric patients and their attitudes towards treating children. The respondents were asked to rate the quality of their undergraduate dental education in preparing them to treat child patients under three years of age, between three and five years of age, between six and nine years of age, and between ten and sixteen years of age. The answers were given on a 5-point answer scale ranging from $1=$ not at all well to $5=$ =very well. In addition, they were asked to indicate their disagreement/agreement with the statements "Dental school prepared me well to treat children" and "My clinical experiences in dental school prepared me well to treat child patients." Answers were given on a 5-point answer scale ranging from $1=$ disagree strongly to $5=$ agree strongly. 
Questions in the third part of the survey were concerned with the dentists' willingness to treat child patients in general. Those dentists who indicated that they treated child patients were asked to supply additional information about the types of treatment they provided for child patients. They were also asked whether they referred children to specialists and specifically which types of oral health care needs they referred. In addition, they were asked whether they provided special accommodations for child patients, which difficulties they encountered when treating pediatric patients, and which best practices they used when managing the behavior of child patients.

As shown in Table 1, descriptive statistics (frequencies/percentages) were used to describe the respondents' perception of their undergraduate education in pediatric dentistry by adding the responses in the two negative and the two positive response categories respectively. In Table 2 , the respondents were divided according to a median split of their combined responses to the two questions "Dental school prepared me well to treat children" and "My clinical experiences in dental school prepared me well to treat child patients"; the average responses of the respondents in these two groups were compared with independent $t$-tests. Table 3 provides the findings concerning the relationships (correlations) between educational experiences about treating children and professional behavior. Finally, Table 4 presents the frequencies and percentages of dentists who provided certain types of treatments categorized by the two groups of dentists with worse vs. better self-reported educational experiences concerning the treatment of child patients. Chi square tests were conducted to test whether the responses of these two groups of dentists differed.

\section{Results}

Most respondents practiced either in a solo practice (63.5 percent), a partnership (12.9 percent), or an associateship (10.4 percent). About one-third of the respondents practiced in a rural (12.9 percent) or small town setting (18.3 percent), a second third in a moderate-sized city ( 35.7 percent), and the last third practiced in a suburb near a large city ( 27.2 percent) or a large city ( 5.4 percent). The respondents treated on average 45.2 adult patients (range: 25 to 180 ) per week and 14.9 patients under the age of sixteen years (range 0 to 200) per week. Only nine dentists (3.8 percent) indicated that they did not treat any children.

\begin{tabular}{|c|c|c|c|c|}
\hline $\begin{array}{l}\text { How well did your dental education prepare you } \\
\text { for managing ... }\end{array}$ & Negative & Neutral & Positive & Mean \\
\hline pediatric patients $<3$ years* & $\begin{array}{c}151 \\
65.9 \%\end{array}$ & $\begin{array}{c}43 \\
18.8 \%\end{array}$ & $\begin{array}{c}35 \\
15.3 \%\end{array}$ & 2.28 \\
\hline pediatric patients $3-5$ years old* & $\begin{array}{c}55 \\
23.9 \%\end{array}$ & $\begin{array}{c}91 \\
39.6 \%\end{array}$ & $\begin{array}{c}84 \\
36.5 \%\end{array}$ & 3.21 \\
\hline pediatric patients 6-9 years old* & $\begin{array}{c}18 \\
7.9 \%\end{array}$ & $\begin{array}{c}69 \\
30 \%\end{array}$ & $\begin{array}{c}143 \\
62.2 \%\end{array}$ & 3.77 \\
\hline pediatric patients $10-16$ years old* & $\begin{array}{c}11 \\
4.8 \%\end{array}$ & $\begin{array}{c}34 \\
14.8 \%\end{array}$ & $\begin{array}{c}185 \\
80.4 \%\end{array}$ & 4.13 \\
\hline Dental school prepared me well for treating children.** & $\begin{array}{c}54 \\
23.5 \%\end{array}$ & $\begin{array}{c}83 \\
36.1 \%\end{array}$ & $\begin{array}{c}93 \\
40.4 \%\end{array}$ & 3.21 \\
\hline $\begin{array}{l}\text { My clinical experiences in dental school prepared me } \\
\text { well to treat child patients.** }\end{array}$ & $\begin{array}{c}59 \\
25.5 \%\end{array}$ & $\begin{array}{c}95 \\
41.1 \%\end{array}$ & $\begin{array}{c}77 \\
33.4 \%\end{array}$ & 3.10 \\
\hline
\end{tabular}

*Answers were given on a scale from $1=$ not at all well to $5=$ very well $(1 \& 2=$ negative responses; $3=$ neutral responses; $4 \& 5=$ positive responses).

**Answers were given on a scale from $1=$ disagree strongly to $5=$ agree strongly $(1 \& 2=$ negative responses; $3=$ neutral responses; $4 \& 5=$ positive responses). 


\section{Perceived Quality of Dental Education About Treating Pediatric Patients}

As displayed in Table 1, the respondents rated their dental education concerning the treatment of pediatric patients under the age of three years the most negatively (mean $=2.28$ on a 5 -point scale with $1=$ not at all well to $5=$ very well). Nearly two-thirds of the respondents (65.9 percent) described their education as negative, while 18.8 percent were neutral and only 15.3 percent were positive. Concerning the treatment of patients between three and five years of age, a smaller but still substantial percentage of 23.9 percent of the respondents reported negative educational experiences, while 39.56 percent were neutral and a little more than a third of the respondents (36.5 percent) were positive. Only 7.9 percent of the respondents did not feel well prepared to treat six- to nine-year-old child patients, and only 4.8 percent felt poorly prepared to treat ten- to sixteenyear-old patients. On average, the dentists described their educational experiences concerning treating pediatric patients in general and their clinical educational experiences with pediatric patients in a neutral fashion (means: 3.21 and 3.10 on a 5-point scale).

Table 2. Average practice characteristics and attitudes of respondents with less vs. more positive educational experiences concerning the treatment of pediatric patients

Less Positive Educational More Positive Educational $\quad p$ Experiences Experiences

\section{Practice characteristics:}

My practice is set up in a way that I can treat children.

3.62

$\mathrm{SD}=1.039$

My staff is comfortable treating children.

My staff is knowledgeable about treating children.

Financial compensation for treating children is inadequate.

\section{Attitudes:}

Like to treat children $<6$ years.

Like to treat children $>6$ years.

Children are often unable to tolerate treatment in the general dentist office.
3.80

$\mathrm{SD}=0.869$

3.65

$\mathrm{SD}=0.950$

3.67

$\mathrm{SD}=1.192$

2.60

$\mathrm{SD}=1.115$

3.56

$\mathrm{SD}=0.980$

2.92

$\mathrm{SD}=1.203$
3.99

$\mathrm{SD}=0.784$

4.19

$\mathrm{SD}=0.705$

4.08

$\mathrm{SD}=0.709$

3.33

$\mathrm{SD}=1.106$

3.16

$\mathrm{SD}=1.169$

3.98

$\mathrm{SD}=0.935$

2.59

$\mathrm{SD}=1.119$
0.003

$<0.001$

$<0.001$

0.037

Table 3. Correlations between educational variables and best practices and challenges

\section{Well Prepared to Treat 3- to 5 Year-Old Patients}

Well Prepared
to Treat 6- to 9-
Year-Old Patients

My practice is set up to treat child patients.

My staff is knowledgeable.

My staff is comfortable.

\section{Attitudes:}

Like to treat $<6$ year old patients.

Like to treat $>6$ year old patients.

Professional behavior:

Sum of Tx provided

${ }^{*} \mathrm{p}<.05 ;{ }^{* *} \mathrm{p}<.01 ; * * * \mathrm{p}<.001$
$237^{* * *}$

$\begin{array}{rrrr}.237^{* * *} & .245^{* * *} & .245^{* * *} & .310^{* * *} \\ .267^{* * *} & .238^{* * *} & .268^{* * *} & .311^{* * *} \\ .259^{* * *} & .232^{* * *} & .238^{* * *} & .313^{* * *} \\ & & & \\ .360^{* * *} & .307^{* * *} & .342^{* * *} & .375^{* * *} \\ .248^{* * *} & .281^{* * *} & .267^{* * *} & .303^{* * *} \\ & & & .214^{* *} \\ .216^{* *} & .181^{*} & .172^{*} & \end{array}$

Clinical

Experiences

Prental Schoo Well 


\begin{tabular}{|c|c|c|c|c|c|c|c|}
\hline \multicolumn{8}{|c|}{ Which of the following treatments do you perform in pediatric patients, and which do you refer to other dental care providers? } \\
\hline & \multicolumn{3}{|c|}{ Less Positive Educational Experiences } & \multicolumn{4}{|c|}{ More Positive Educational Experiences } \\
\hline & I do all. & I do some. & I refer all. & I do all. & I do some. & I refer all. & $\mathrm{p}$ \\
\hline Oral exams & $\begin{array}{c}87 \\
83.7 \%\end{array}$ & $\begin{array}{c}17 \\
16.3 \%\end{array}$ & 0 & $\begin{array}{c}106 \\
97.2 \%\end{array}$ & $\begin{array}{c}3 \\
2.8 \%\end{array}$ & 0 & .001 \\
\hline Fluoride treatment & $\begin{array}{c}83 \\
81.4 \%\end{array}$ & $\begin{array}{c}19 \\
18.6 \%\end{array}$ & 0 & $\begin{array}{c}96 \\
88.1 \%\end{array}$ & $\begin{array}{c}10 \\
9.2 \%\end{array}$ & $\begin{array}{c}3 \\
2.8 \%\end{array}$ & .039 \\
\hline Cleanings & $\begin{array}{c}83 \\
79.8 \%\end{array}$ & $\begin{array}{c}21 \\
20.2 \%\end{array}$ & 0 & $\begin{array}{c}95 \\
87.2 \%\end{array}$ & $\begin{array}{c}11 \\
10.1 \%\end{array}$ & $\begin{array}{c}3 \\
2.8 \%\end{array}$ & .033 \\
\hline Radiographs & $\begin{array}{c}80 \\
77.7 \%\end{array}$ & $\begin{array}{c}23 \\
22.3 \%\end{array}$ & 0 & $\begin{array}{c}94 \\
85.5 \%\end{array}$ & $\begin{array}{c}15 \\
13.6 \%\end{array}$ & $\begin{array}{c}1 \\
.9 \%\end{array}$ & .167 \\
\hline Sealants & $\begin{array}{c}77 \\
76.2 \%\end{array}$ & $\begin{array}{c}23 \\
22.8 \%\end{array}$ & $\begin{array}{c}1 \\
1 \%\end{array}$ & $\begin{array}{c}92 \\
87.6 \%\end{array}$ & $\begin{array}{c}13 \\
12.4 \%\end{array}$ & 0 & .081 \\
\hline Restorations & $\begin{array}{c}56 \\
54.4 \%\end{array}$ & $\begin{array}{c}47 \\
45.6 \%\end{array}$ & $\begin{array}{c}0 \\
75.2 \%\end{array}$ & $\begin{array}{c}82 \\
23.9 \%\end{array}$ & $\begin{array}{l}26 \\
.9 \%\end{array}$ & 1 & .003 \\
\hline Extractions & $\begin{array}{c}35 \\
33.7 \%\end{array}$ & $\begin{array}{c}62 \\
59.6 \%\end{array}$ & $\begin{array}{c}7 \\
6.7 \%\end{array}$ & $\begin{array}{c}55 \\
50.5 \%\end{array}$ & $\begin{array}{c}52 \\
47.7 \%\end{array}$ & $\begin{array}{c}2 \\
1.8 \%\end{array}$ & .018 \\
\hline Crowns & $\begin{array}{c}34 \\
33.3 \%\end{array}$ & $\begin{array}{c}53 \\
52.0 \%\end{array}$ & $\begin{array}{c}15 \\
14.7 \%\end{array}$ & $\begin{array}{c}48 \\
48.5 \%\end{array}$ & $\begin{array}{c}37 \\
37.4 \%\end{array}$ & $\begin{array}{c}14 \\
14.1 \%\end{array}$ & .073 \\
\hline Endodontics & $\begin{array}{c}14 \\
14.3 \%\end{array}$ & $\begin{array}{c}44 \\
44.9 \%\end{array}$ & $\begin{array}{c}40 \\
40.8 \%\end{array}$ & $\begin{array}{c}35 \\
33 \%\end{array}$ & $\begin{array}{c}45 \\
42.5 \%\end{array}$ & $\begin{array}{c}26 \\
24.5 \%\end{array}$ & .003 \\
\hline Orthodontics & $\begin{array}{c}3 \\
3 \%\end{array}$ & $\begin{array}{c}18 \\
17.8 \%\end{array}$ & $\begin{array}{c}80 \\
79.2 \%\end{array}$ & $\begin{array}{c}10 \\
9.6 \%\end{array}$ & $\begin{array}{c}19 \\
18.3 \%\end{array}$ & $\begin{array}{c}75 \\
72.1 \%\end{array}$ & .141 \\
\hline
\end{tabular}

However, approximately one out of four dentists rated their overall dental education about treating pediatric patients as well as their clinical experiences concerning the treatment of children as negative ( 23.5 percent and 25.5 percent).

\section{Practice Characteristics and Attitudes Towards Treating Child Patients}

In order to compare dentists with more positive evaluations of their educational experiences with dentists who provided more negative evaluations, an average score of the two responses to the questions "Dental school prepared me well to treat children" and "My clinical experiences in dental school prepared me well to treat child patients" was computed for each respondent. The respondents were then categorized based on a median split of these average responses with the lower 50 percent (under an average score of 3.3) being assigned to the category "Less positive educational experiences," while the upper 50 percent of the respondents was assigned to the category "More positive educational experiences." Dentists with more positive educational experiences were on average younger (46.02 vs. 49.55 years; $\mathrm{p}=.022)$ and graduated from dental school later (1984 vs. $1980 ; \mathrm{p}=.012$ ) than respondents with less positive educational experiences.

Concerning the respondents' practice characteristics, it was predicted that the quality of their educational experiences with the treatment of child patients would be related to the degree to which they organized their practice to be able to treat children and the capacity of their staff to treat pediatric patients. As shown in Table 2, respondents with more positive educational experiences agreed more strongly with the statement that their practice was set up in a way that facilitated the treatment of children compared to respondents who had less positive educational experiences ( 3.99 vs. $3.63 ; \mathrm{p}=.003$ ). In addition, dentists with more positive educational experiences in pediatric dentistry were more likely to report that their staff was comfortable and knowledgeable about treating children (4.19 vs. $3.80 ; \mathrm{p}<.001 ; 4.08$ vs. $3.65 ; \mathrm{p}<.001)$. Financial compensation for treating children was judged as more inadequate by dentists who felt less well prepared by their dental school programs than by those respondents who felt better prepared (3.67 vs. $3.33 ; p=.033$ ). In addition, the 
respondents' answers concerning their educational experiences about treating child patients in different age groups and their practice characteristics were significantly correlated (see Table 3 ). The more the respondents agreed that their undergraduate dental education had prepared them well to treat three- to five-year-old patients and six- to nine-year-old patients, the more they agreed that their practice was set up to treat child patients $(\mathrm{r}=.24 ; \mathrm{p}<.001 ; \mathrm{r}=.25$; $\mathrm{p}<.001)$, that their staff was knowledgeable $(\mathrm{r}=.27$; $\mathrm{p}<.001 ; \mathrm{r}=.24 ; \mathrm{p}<.001)$, and that their staff was comfortable treating child patients $(\mathrm{r}=.26 ; \mathrm{p}<.001$; $\mathrm{r}=.23 ; \mathrm{p}<.001$ ).

Concerning the respondents' attitudes about treating pediatric patients, it was expected that respondents with more positive educational experiences would have more positive attitudes toward treating child patients than dentists with less positive educational experiences. This hypothesis was supported by the data as displayed in Table 2. Dentists with more positive educational experiences were more likely to report that they liked treating children under the age of six years (3.16 vs. $2.60 ; p<.001)$ as well as over six years of age ( 3.98 vs. $3.56 ; p<.001)$ compared to dentists with less positive educational experiences. Dentists who had a less positive opinion of their pediatric dentistry education were more likely to report that children were unable to tolerate treatment in the general dentist office (2.92 vs. 2.59; $\mathrm{p}=.037$ ) than the respondents with more positive educational experiences in this area. In addition, it was also found that the better the respondents were prepared to treat three- to five-year-old patients and six- to nine-year-old patients, the more they liked to treat patients under the age of six years $(r=.36$; $\mathrm{p}<.001 ; \mathrm{r}=.31 ; \mathrm{p}<.001)$ and patients over six years of age $(r=.25 ; \mathrm{p}<.001 ; \mathrm{r}=.28 ; \mathrm{p}<.001)$ (see Table 3$)$.

\section{Dental Education and Professional Behavior}

All 241 respondents answered the questions concerning their general background, practice characteristics, and attitudes concerning the treatment of children. However, the questions concerning the types of treatment provided for children, referrals of children, behavior management techniques used, and accommodations provided for pediatric patients were only answered by the 232 respondents who had indicated that they treated children. In comparison to respondents who did not report that they were well trained in pediatric dentistry, dentists who perceived that they had been well prepared to treat children between three and six years of age and between six and nine years of age provided more different types of treatment for pediatric patients $(\mathrm{r}=.22 ; \mathrm{p}<.01$; $\mathrm{r}=.18 ; \mathrm{p}<.05$ ), were less likely to refer these patients $(\mathrm{r}=20 ; \mathrm{p}<.01 ; \mathrm{r}=.20 ; \mathrm{p}<.01)$, and were more likely to offer special arrangements $(\mathrm{r}=.14 ; \mathrm{p}<.05)$ and more special accommodations for pediatric patients $(\mathrm{r}=.12 ; \mathrm{p}<.10)$.

Table 4 presents an overview of the frequencies/ percentages of different kinds of treatment provided by respondents with less vs. more positive educational experiences about treating pediatric patients. Respondents with more positive pediatric dentistry experiences were significantly more likely to conduct all oral exams (97.2 percent vs. 83.7 percent; $p<.001$ ), all fluoride treatments ( 88.1 percent vs. 81.4 percent; $\mathrm{p}=.039)$, all cleanings ( 87.2 percent vs. 79.8 percent; $\mathrm{p}=.033$ ), all restorations (75.2 percent vs. 54.4 percent; $\mathrm{p}=.003$ ), all extractions (50.5 percent vs. 33.7 percent; $p=.018)$, and all endodontic treatment of child patients (33 percent vs. 14.3 percent; $p=.003$ ) than the respondents with less positive educational experiences. While the majority of respondents in both groups referred child patients for orthodontic treatment (72.1 percent vs. 79.2 percent; $n$.s.), respondents with less positive experiences were more likely to refer patients who needed endodontic treatment (40.8 percent vs. 24.5 percent; $p=.003$ ) and patients who needed extractions ( 6.7 percent vs. 1.8 percent; $\mathrm{p}=$.018).

\section{Discussion}

Only nine respondents ( 3.8 percent) indicated that they did not treat any children. This percentage of dentists who did not provide pediatric care is lower than the findings in Seale and Casamassimo's national survey in 2001, which was 9 percent. ${ }^{12}$ Overall, this finding is quite encouraging, because general practitioners are clearly needed to meet the oral health care needs of pediatric patients in the United States. They make up the vast majority of dental practitioners, and any plan to meet the unmet dental health care needs of children will need to focus on general dentists and their education concerning treating pediatric patients. However, it is discouraging that only 40.4 percent of the respondents reported that their undergraduate dental education had prepared them well to treat child patients and only 33.4 percent indicated that their clinical experiences during dental school had prepared them well to treat children. Even more note- 
worthy is the fact that 85 percent of respondents did not feel well prepared to treat pediatric patients under three years of age. Given the fact that the American Dental Association as well as the American Academy of Pediatric Dentistry recommend a first dental visit for all children on eruption of their first tooth but no later than twelve months of age, ${ }^{16,17}$ the question arises whether parents of these young children will actually find providers who are willing to see their children. A recent study by Siegal and Marx highlights this problem with data from Ohio. ${ }^{18}$ It would be interesting to ask graduating seniors whether they had gained any clinical experience with treating very young patients and were taught, for example, how to perform a knee to knee exam with a toddler.

In addition, it is noteworthy that only 33.4 percent of these respondents who graduated in the past fifty-five years indicated that clinical experiences in dental school had prepared them well to treat child patients. If two-thirds of the respondents did not agree that they had positive clinical experiences in this area, it raises the question how many of the currently graduating seniors think that their clinical experiences had prepared them well. It would be interesting to find out how many graduating seniors had never placed an amalgam in a primary tooth or extracted a primary tooth or restored a primary tooth with a stainless steel crown.

Overall, the data strongly support the hypotheses that dental education affects practitioners' practice characteristics, attitudes, and professional behavior concerning treating pediatric dental patients. When the respondents were divided into a group with more positive educational experiences versus a group with less positive educational experiences, the results indicate that the better-educated dentists were more likely to have set up their practices to treat children and had staff members who were both more comfortable and more knowledgeable about treating children than the less well-trained dentists. In addition, they were more likely to have positive attitudes towards treating child patients, both younger and older than six years of age. Given the finding that only 21.1 percent of children under the age of six years saw a dentist in the year $2000,{ }^{19}$ it becomes crucial to consider how dental education can contribute to increasing the number of general dentists who are willing to see children under six years of age and feel comfortable and well prepared to do so.

The findings also show that dentists with more positive educational experiences are more likely to provide more types of treatment for pediatric patients and are less likely to refer child patients to specialists than dentists with less positive educational experiences. It is especially interesting to note the differences between the groups in their responses concerning the degree to which they provide sealants, restorations, crowns, extractions, and endodontic treatment. Underserved children are likely to need these types of procedures, so training future providers to be comfortable to provide these services is crucial.

Overall, these data stressed the importance of dental education for future providers' practice characteristics, attitudes, and professional behavior concerning the treatment of pediatric dental patients. These findings together with the findings by Dao et al. in 2005 concerning the treatment of special needs patients ${ }^{15}$ and by Smith et al. in 2006 concerning the treatment of underrepresented minority patients ${ }^{14}$ support the argument that the scope and quality of dental school educational experiences influence future providers' attitudes and professional behaviors concerning the treatment of underserved patients. The combined outcomes of these three studies send the message that dental students' education concerning providing care for underserved patient groups has the potential to make a contribution to solving the access to care problem in the United States.

In the context of considering how to bring better oral health care to children at an early age, it seems also worthwhile to mention that the American Academy of Pediatrics (AAP) revised its policy on infant oral health care in 2003 and recommended the establishment of a "dental home" for all infants by age one. ${ }^{20}$ This growing acknowledgment by pediatricians of the significance of good oral health for all children from an early age on is quite encouraging and should alert dental educators to the importance of preparing future health care providers to be able to provide infant oral health evaluations and treat children from a very early age on.

Limitations of this study are that data were only collected from dentists in one state, namely Michigan, and that only 48.2 percent of the sample responded. While this response rate is acceptable for a mailed survey, ${ }^{21}$ it would have been interesting to see whether the results would have been different if the response rate had been higher. One might suspect that the nonresponding dentists could potentially have been more negative in their attitudes towards the treatment of pediatric patients than the responding dentists. 


\section{Conclusions}

This study showed that a large percentage of the respondents did not feel well prepared to treat child patients, especially if these child patients were very young. In addition, it is important to note that two-thirds of the respondents did not evaluate their clinical experiences with the treatment of children in a positive light. These deficits in educational experiences are troubling because dentists' perceptions of the quality of their educational experiences were clearly related to their willingness to provide a variety of different treatments for children as well as their attitudes about pediatric care. Dentists with more positive educational experiences about treating children were more likely to report that they liked treating children and maintained a practice where children can be treated comfortably than did dentists with less positive experiences. In addition, they were more likely to provide more extensive care for pediatric patients and less likely to refer these patients than those dentists with less positive educational experiences. These findings strongly suggest that educational experiences concerning the treatment of pediatric dental patients will shape future dental care providers' attitudes and professional behavior. Given the inadequate access to dental care for children, it seems crucial to carefully evaluate undergraduate dental curricula to ensure that future dental care providers receive sufficient educational and especially clinical experiences concerning the treatment of child patients.

\section{Acknowledgments}

This study was supported by a Summer Research Program Fellowship from the University of Michigan School of Dentistry to the first author. We want to thank Dean Peter Polverini for his support of this study by writing a cover letter accompanying the survey and the Michigan Dental Association for providing us with the addresses of their members.

\section{REFERENCES}

1. U.S. Department of Health and Human Services. Oral health in America: a report of the surgeon general. NIH Publication 00-4713. Rockville, MD: National Institute of Dental and Craniofacial Research, National Institutes of Health, 2000:7.

2. Children's Dental Health Project. Children's oral health fact sheets. At: www.cdhp.org/CDHPPubs/FactSheets.asp. Accessed: August 19, 2006.
3. Acs G, Lodolini G, Kaminsky S, Cisneros GJ. Effect of nursing caries on body weight in a pediatric population. Pediatr Dent 1992;14:302-5.

4. Ayhan H, Suskan E, Yildirim S. The effect of nursing or rampant caries on height, body weight, and head circumference. J Clin Pediatr Dent 1996;20(3):209-12.

5. Reinsine ST. Dental health and public policy: the social impact of disease. Am J Public Health 1985;75(1):2730.

6. Gift HC, Reisine ST, Larach DC. The social impact of dental problems and visits. Am J Public Health 1992;82(12):1663-8.

7. Hollister MC, Weintraub JA. The association of oral status with systemic health, quality of life, and economic productivity. J Dent Educ 1993;57(12):901-12.

8. Peterson J, Niessen L, Nana Lopez G. Texas public school nurses' assessment of children's oral health status. J School Health 1999;69(2):69-72.

9. Schechter N. The impact of acute and chronic dental pain on child development. J Southeastern Society Pediatr Dent 2000;6(2): 16.

10. Ramage S. The impact of dental disease on school performance. J Southeastern Society Pediatr Dent 2000;6(2):26.

11. National Center for Education in Maternal and Child Health. Oral health and learning. Vol. 2001. Washington, DC: National Center for Education in Maternal and Child Health and Georgetown University, 2001.

12. Seale NS, Casamassimo PS. Access to dental care for children in the United States. J Am Dent Assoc 2003;134(12):1630-40.

13. Lekic PC, Sanche N, Odlum O, deVries J, Wiltshire WA. Increasing general dentists' provision of care to child patients through changes in the undergraduate pediatric dentistry program. J Dent Educ 2005;69(3):371-7.

14. Smith CS, Ester CV, Inglehart MR. Dental education and care for underserved patients: an analysis of students' intentions and alumni behavior. J Dent Educ 2006;70(4):398-408.

15. Dao LP, Zwetchkenbaum S, Inglehart MR. General dentists and special needs patients: does dental education matter? J Dent Educ 2005;69(10):1107-15.

16. American Dental Association. ADA statement on early childhood caries. At: www.ada.org/prof/resources/positions/statements/caries.asp. Accessed: June 22, 2004.

17. American Academy of Pediatric Dentistry. 2005-06 oral health policies and clinical guidelines: oral health policies - policy on the dental home. At: www.aapd.org/ media/policies_guidelines/p_dentalhome.pdf. Accessed: September 25, 2005.

18. Siegal MD, Marx ML. Ohio dental care providers' treatment of young children, 2002. J Am Dent Assoc 2005;136(11):1583-91.

19. Brown E, Manski Dental Services. Use, expenses, and sources of payment, 1996-2000. MEPS Research Findings No. 20. AHRQ Publication No. 04-0018.

20. American Academy of Pediatrics policy statement- - section on pediatric dentistry. Pediatrics 2003;111:1111-6.

21. Asch DA, Jedrziewski MK, Christakis NA. Response rates to mail surveys published in medical journals. J Clin Epidemiol 1997;50(10):1129-36. 